Research Article

\title{
In Situ Stress Inversion and Distribution Characteristics of Tunnel Based on Numerical Simulation and Neural Network Technology
}

\author{
Pei Zhang \\ Xi'an University of Science and Technology, Xi an 710000, China \\ Correspondence should be addressed to Pei Zhang; zhangpei@xust.edu.cn
}

Received 3 February 2021; Revised 18 February 2021; Accepted 22 February 2021; Published 19 March 2021

Academic Editor: Haiyan Wang

Copyright (c) 2021 Pei Zhang. This is an open access article distributed under the Creative Commons Attribution License, which permits unrestricted use, distribution, and reproduction in any medium, provided the original work is properly cited.

\begin{abstract}
According to the geological conditions of the study area, the measured data of in situ stress was analyzed and the influence degree of buried depth was obtained. A numerical simulation research model with full consideration of fault structure and surface characteristics is established, and boundary condition functions with variables are used. The neural network optimized by genetic algorithm is used to establish the nonlinear relationship between the measured value and the simulated value of the variable boundary condition, and the optimal boundary condition function is obtained. Finally, the in situ stress in the study area was predicted. Through the analysis of the in situ stress field in the research target area, the stress boundary conditions are provided for the follow-up study, and the practical basis for the division of the dangerous area of the surrounding rock of the deep and long tunnel is provided.
\end{abstract}

\section{Introduction}

For tunnels coal mines and other deep buried underground projects, the initial in situ stress field is the result of vertical load and tectonic stress [1]. At the same time, the initial stress field also determines the mechanical properties of engineering rock mass after excavation to a large extent $[2,3]$. The study of initial in situ stress field can provide basis for later engineering support dangerous area evaluation and construction mode selection. At present, the research of in situ stress field mainly includes regression analysis, boundary load, function back analysis, and intelligent inversion method based on neural network technology $[4,5]$.

However, for mountain tunnels, the in situ stress is mainly measured. The results of in situ stress inversion are not rich; in particular, the research on the distribution characteristics of in situ stress under the influence of faults is relatively scarce [6]. Although the measured in situ stress can better reflect the occurrence of the real in situ stress, its cost is high and it cannot fully reflect the characteristics of the overall in situ stress in the study area [7].
Due to the appearance of faults and other structural zones, the distribution of initial in situ stress field is uneven. In particular, the stress concentration near the fault is more prominent. The formation of fault is the fracture structure produced by the action of geological tectonic movement [8-10]. In particular, reverse faults are mainly formed by horizontal compression and gravity. The stress concentration of the fault is more obvious [11].

However, the finite element method and the finite difference method are more convenient to simulate the continuous medium but are not good at simulating fault structure. The three-dimensional discrete element method (3DEC) is a kind of discrete element method which can directly calculate the dislocations of faults. It is possible to simulate faults and other fault structures $[12,13]$.

In this paper, a numerical model with faults is established according to the geological characteristics of the study area and then a neural network inversion model based on genetic algorithm is proposed. According to the numerical calculation data and the inversion model, the independent 
variables in the boundary conditions are used as training samples and the accurate boundary conditions are obtained, and then the distribution characteristics of the initial in situ stress field in the tunnel area are analyzed.

\section{Project Overview}

2.1. Geological Survey. Jingzhai tunnel is the administrative region of Jinghong City, Yunnan Province, as shown in Figure 1. The total length of the tunnel is $9509 \mathrm{~m}$ and the maximum buried depth of the construction tunnel is $711 \mathrm{~m}$. The area is covered with clay coarse breccia soil and colluvial gravel soil. Underlying bedrock is shale with mudstones and stonelime porphyryba saltcoal line fault breccia. Mamaoxiaozhai gabuto fault: strike is about $\mathrm{N} 10^{\circ}$ to $30^{\circ} \mathrm{W}$ and it extends in wavy curve. The line intersects with the fault surface and the included angle is about $58^{\circ}$. The strike of the strata is parallel to the fault line which is characterized by compressional reverse fault. The width of the fault fracture zone is about $20 \mathrm{~m}$ with strong cataclastic alteration rhombic structure wrinkling dikes and scratches. The main components of fault breccia are breccia mudstone and a small amount of mylonite. The hanging wall near the line is the Middle Triassic Bangsha formation and the footwall is the upper Permian Longtan Formation and the lower Permian Maokou Formation. The fault is a large angle oblique line and is located near the line which has a great impact on the tunnel.

2.2. In Situ Stress Measurement Characteristics. In the geological exploration stage of the tunnel, in order to fully understand the distribution of in situ stress in the tunnel area, five in situ stress test boreholes are arranged along the Jingzhai tunnel, and the test data are shown in Figures 2 and 3. It is especially pointed out that, due to the broken rock mass, the corresponding test data cannot be obtained in the borehole near the fault. It is especially pointed out that, due to the broken rock mass, the corresponding test data cannot be obtained in the borehole near the fault [14-16].

According to the in situ stress test results of single hole hydraulic fracturing, it is shown that the maximum horizontal principal stress and the minimum horizontal principal stress increase with the increase of burial depth, and the relationship is approximately linear.

The maximum horizontal principal stress direction is all located in NW direction, which is basically consistent with the maximum principal stress direction of regional tectonic stress field [17-19]. The average value of the ratio of the maximum horizontal principal stress to the minimum horizontal principal stress is 1.75; and the maximum value is 1.92. According to Mohr-Coulomb strength theory, the difference between the two principal stresses is shear stress, and the failure of rock mass is usually caused by shear failure. There is a large shear stress in the horizontal plane, which must be paid enough attention. The variation of maximum and minimum horizontal principal stress with hole depth and the fitting curve are shown in the five following equations:

$$
\begin{aligned}
\sigma_{H} & =0.017 H+1.801, \\
\sigma_{h} & =0.011 H+0.819, \\
\sigma_{H} & =0.021 H+1.442, \\
\sigma_{h} & =0.012 H+0.725, \\
\sigma_{H} & =0.013 H+1.682, \\
\sigma_{h} & =0.007 H+0.904, \\
\sigma_{H} & =0.023 H+1.309, \\
\sigma_{h} & =0.012 H+0.665, \\
\sigma_{H} & =0.028 H+1.487, \\
\sigma_{h} & =0.014 H+0.861 .
\end{aligned}
$$

In the formula, $\sigma_{H}$ is the maximum horizontal principal stress, $\sigma_{h}$ is the minimum horizontal principal stress, and $H$ is the buried depth.

\section{Numerical Calculation Model and Parameter Selection}

3.1. Numerical Modeling. The three-dimensional model of regional in situ stress analysis established in the three-dimensional discrete element numerical software 3DEC is shown in Figure 4. The model coordinate system is the same as the geodetic coordinate system; that is, the east direction is the $X$ direction of the model, the north direction is the $Y$ direction of the model, and the vertical direction is the $Z$ direction of the model. The range of the model is $13 \mathrm{~km}$ from east to west and $6 \mathrm{~km}$ from north to south. In the numerical model, $2600 \times 1200$ grids are divided according to the total hexahedron. The tectonic stress boundary is considered around the model, and the fixed constraint boundary is adopted at the bottom of the model. Mohr-Coulomb model is used for mesh and Coulomb slip model is used for joints.

3.2. Parameter Selection. According to the numerical simulation data and the actual situation of the study area, the deep rock mechanics parameters suitable for regional tectonic calculus are determined as shown in Table 1. Through GSI parameters, the classification index is converted to rock parameters, and Table 2 is obtained. The Coulomb sliding joint model is used to simulate the interface of fault structure. The normal contact stiffness is $27 \mathrm{GPa} / \mathrm{m}$, the tangential contact stiffness is $5.8 \mathrm{GPa} / \mathrm{m}$, and the contact friction coefficient is 0.53 . 


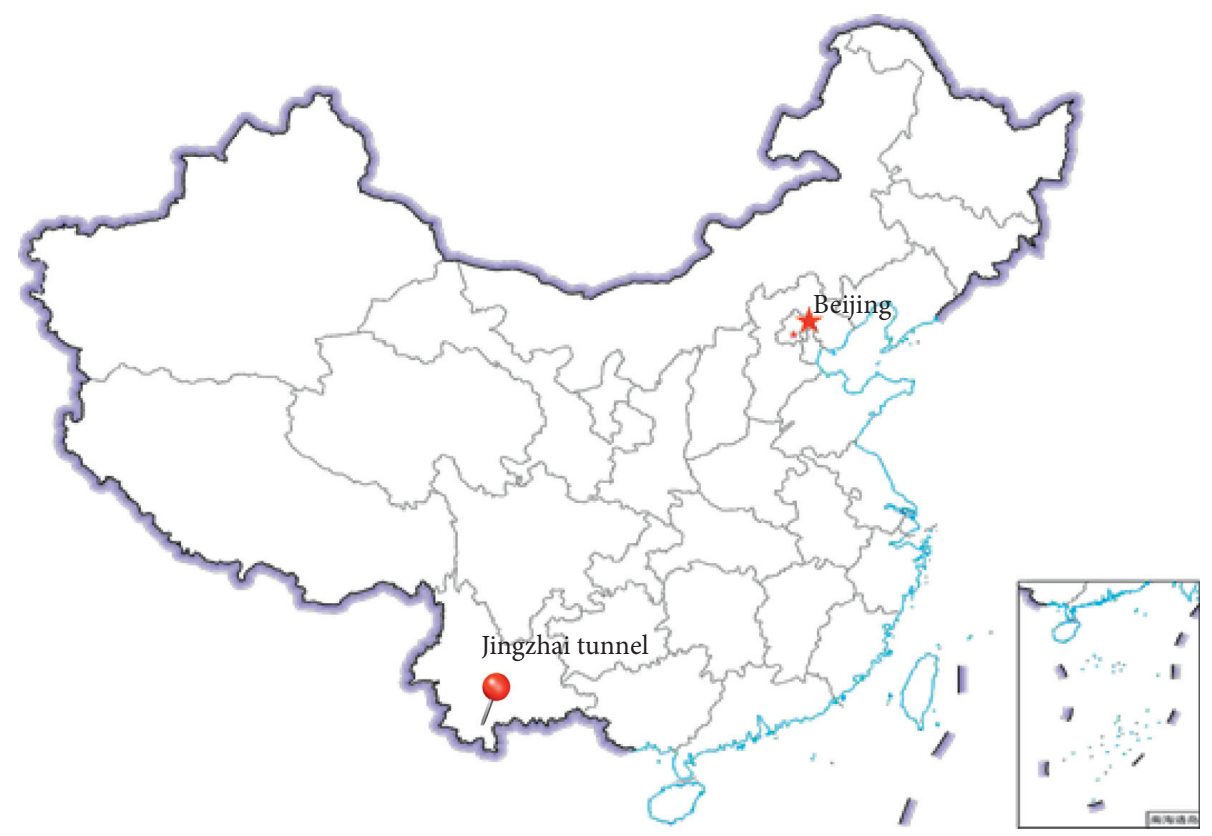

(a)

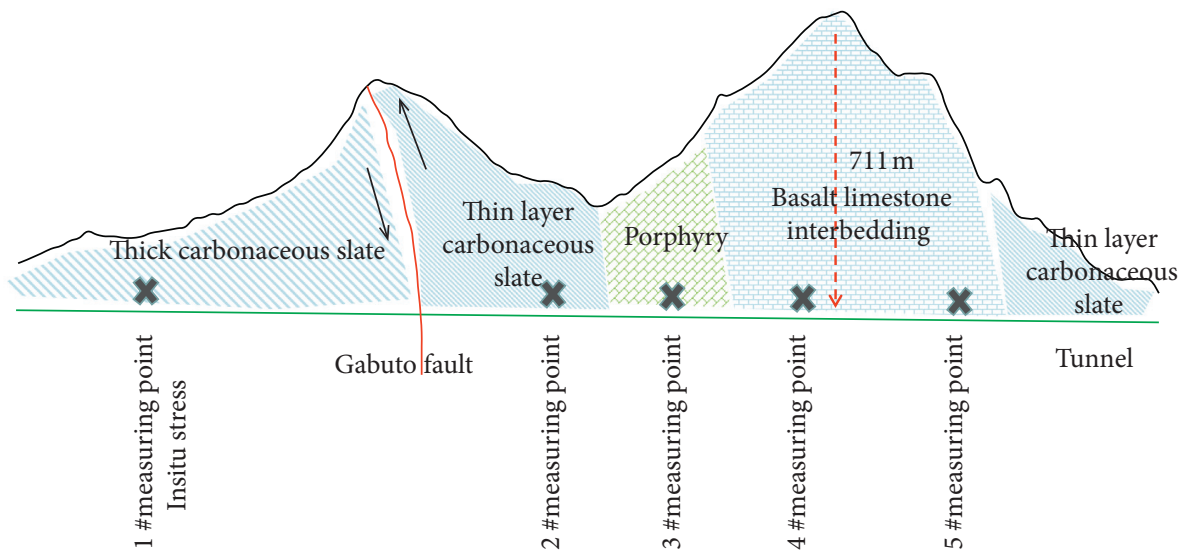

(b)

Figure 1: Research target location and geological section. (a) Research target tunnel location. (b) Tunnel profile and in situ stress measurement points.

3.3. Boundary Conditions. The boundary condition considering depth is established. The vertical stress load is approximated to the weight of overlying strata. According to the research results of Hoek-Brown stress distribution in the world, the ratio $\lambda$ of horizontal stress to vertical stress is linearly related to the reciprocal of depth, so the horizontal boundary condition in $X$ direction is $\sigma_{x}=\lambda(k h+a)=(k h+a)((b / h)+c)$, where $k, a, b$, and $c$ are the independent variables. The $y$ direction horizontal boundary condition is $\sigma_{y}=\omega \sigma_{x}$, where the independent variable $\omega$ is the ratio of $Y$ direction horizontal stress to $X$ direction horizontal stress. The shear stress parallel to the boundary is applied to the boundary condition to simulate the loading of tectonic stress on the boundary $\sigma_{\tau}=\nu h$, where $v$ is the independent variable.

\section{In Situ Stress Inversion Calculation}

4.1. BP Neural Network Optimization Based on Genetic Algorithm. BP neural network based on genetic algorithm can optimize the initial weights and thresholds [20]. The neural network consists of three parts: BP neural network structure, genetic algorithm optimization, and neural network prediction. In this case, the boundary conditions need to be fitted, and the input parameters are 6; the output parameters include the maximum horizontal principal stress and the minimum horizontal principal stress. The structure of neural network is selected as 6 nodes in input layer, 7 nodes in hidden layer, and 2 nodes in output layer. The number of weights is calculated by multiplying the number of input layer nodes by the number of hidden layer nodes 


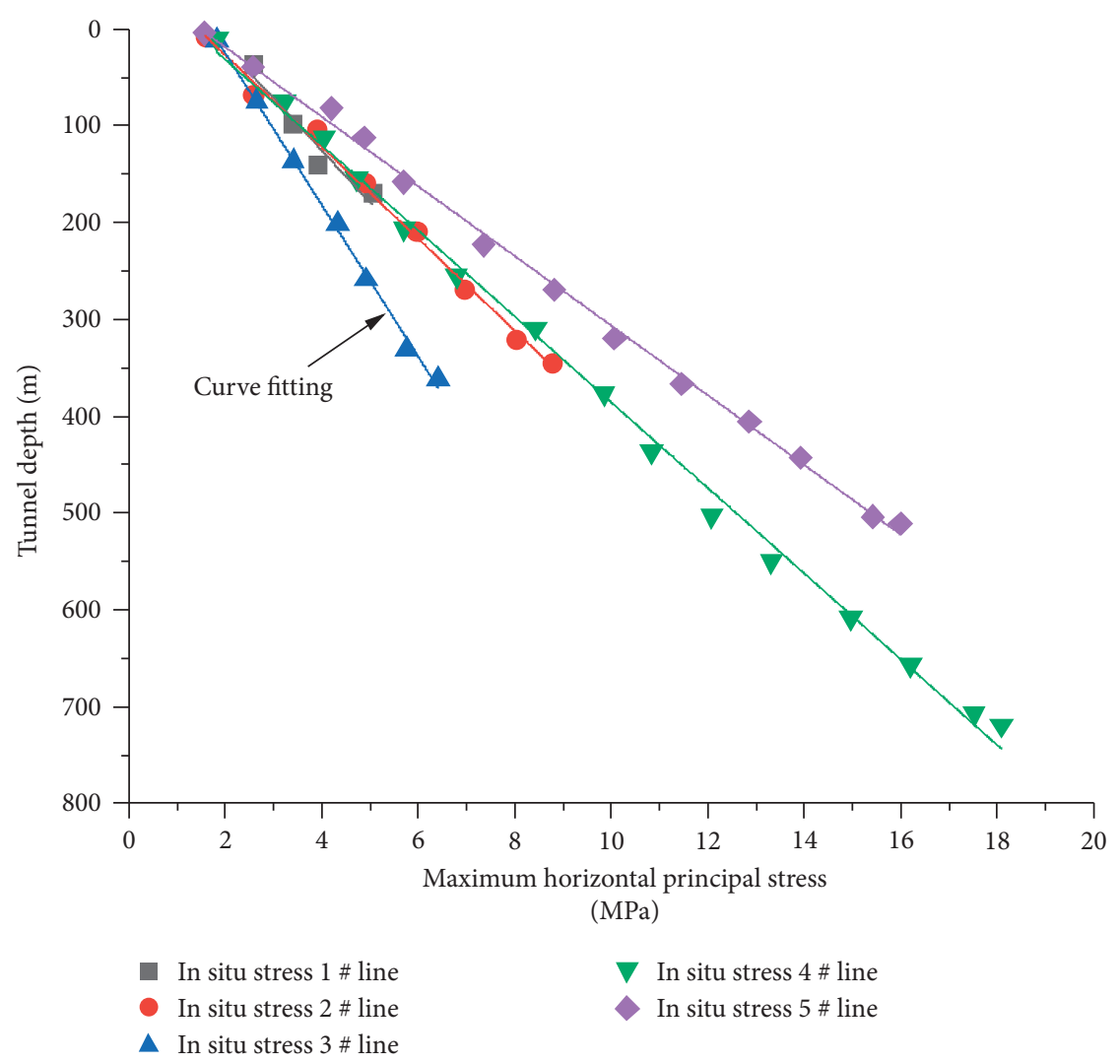

Figure 2: Variation characteristics of maximum horizontal in situ stress with depth.

and multiplying the number of output layer nodes by the number of hidden layer nodes to add 56 weights. The number of hidden layer and output layer nodes is added to 9 thresholds.

The independent variables in the boundary conditions are selected as the input samples of the neural network, and the difference between the simulated values and the measured values is taken as the output samples of the neural network [21, 22]. A neural network based on genetic algorithm is constructed. The trained neural network is used. According to the optimization analysis of the parameters in the neural network, the boundary condition variable value is output when the difference between the measured value and the simulated value is 0 , and the distribution of the in situ stress field in the study area is obtained. The flow chart is shown in Figure 5.

\subsection{Inversion Training and Results}

4.2.1. Inversion Training. According to the difference between the simulated value and the measured value under the boundary conditions of different variables, the absolute values of all the measured points are added up [23-25]. The smaller the value is, the closer the boundary condition is to the real situation. The optimal boundary conditions are obtained by analysis. 25 simulation results are learned and analyzed in this area, and the simulation results are shown in Table 3.
According to the above samples, machine learning is carried out and the values of various factors are adjusted continuously. Finally, the boundary condition closest to the measured value is obtained: $\sigma_{x}=0.44 H+(0.39 / H)+0.77$; $H$ is the burial depth. The horizontal boundary condition in $Y$ direction is applied: $\sigma_{y}=1.4 \sigma_{x}$. The loading of simulated tectonic stress on the boundary is as follows: $\sigma_{v}=0.015 \mathrm{H}$.

4.2.2. In Situ Stress Field Analysis. The maximum horizontal principal stress is the resultant stress in $X$ direction and $Y$ direction. According to the calculation, the in situ stress value obtained by inversion analysis is close to the measured stress value, and the obtained inversion regression stress field can express the main characteristics of the in situ stress field in the engineering area.

The in situ stress information obtained by inversion is shown in Figures 6-8. It can be seen from the figure that the horizontal stress in the $X$ direction of the whole model area is basically close to the horizontal stress in the $Y$ direction, so the direction of the maximum principal stress is approximately NW45, which is basically close to the measured value.

According to the numerical calculation results, the tunnel buried depth, valley, and fault zone have great influence on the in situ stress. The vertical stress is proportional to the buried depth. The horizontal in situ stress also increases with the increase of burial depth. In the fault area, the in situ stress shows obvious discontinuity, the in situ stress value of the broken surrounding rock in the fault is 


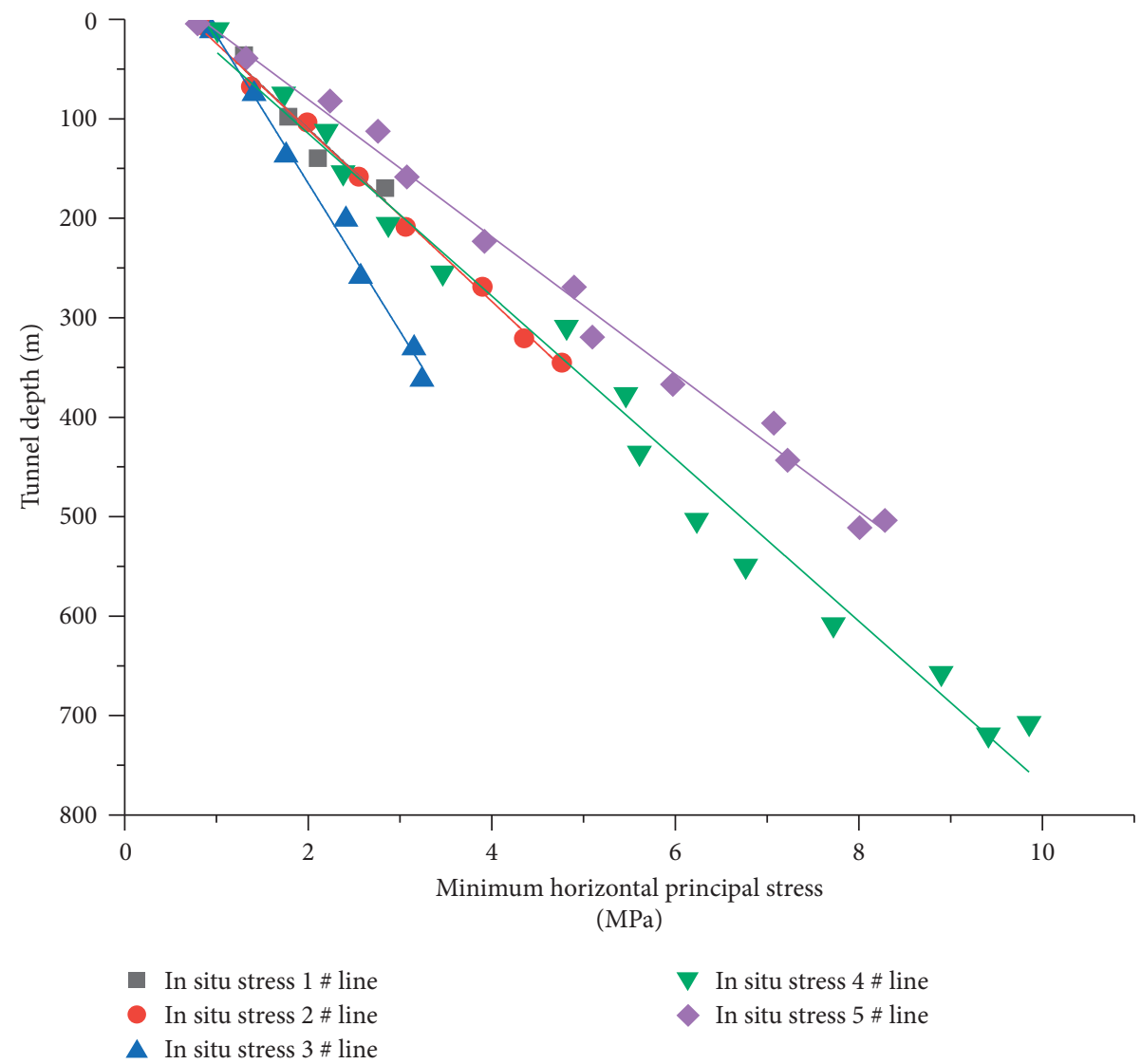

FIGURE 3: Variation characteristics of minimum horizontal in situ stress with depth.

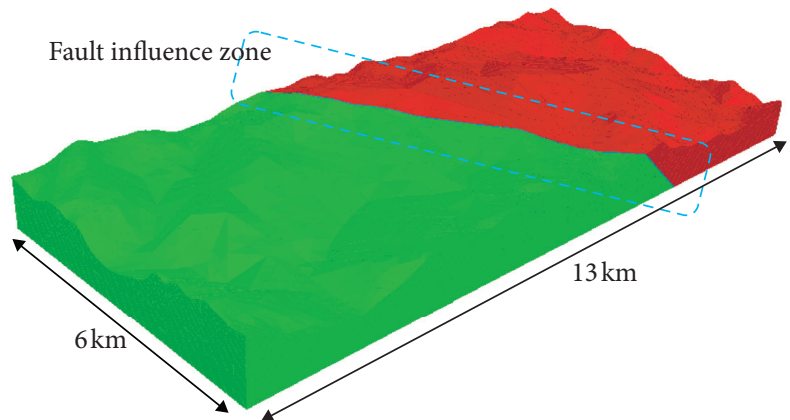

FIgURe 4: 3D numerical model.

TABLE 1: Rock block strength.

\begin{tabular}{lccccc}
\hline Lithology & $\begin{array}{c}\text { Uniaxial compressive } \\
\text { strength }(\mathrm{MPa})\end{array}$ & GSI index & $\begin{array}{c}\text { Rock integrity } \\
\text { coefficient }\end{array}$ & $\begin{array}{c}\text { Blasting damage } \\
\text { coefficient }\end{array}$ & Elastic modulus (GPa) \\
\hline Thick carbonaceous slate & 22 & 73 & 12 & 0.5 & 14 \\
Thin layer carbonaceous & 19 & 55 & 10 & 0.5 & 12 \\
slate & 112 & 75 & 10 & 0.5 & 35 \\
Porphyry & 130 & 46 & 10 & 0.5 & 38 \\
$\begin{array}{l}\text { Basalt limestone } \\
\text { interbedding }\end{array}$ & & & & \\
\hline
\end{tabular}


TABLE 2: Rock mass strength parameters based on GSI classification index.

\begin{tabular}{lccccc}
\hline Lithology & $\begin{array}{c}\text { Cohesion } \\
(\mathrm{MPa})\end{array}$ & Friction angle & $\begin{array}{c}\text { Tensile strength } \\
(\mathrm{MPa})\end{array}$ & $\begin{array}{c}\text { Uniaxial compressive } \\
\text { strength }\end{array}$ & Modulus of deformation (GPa) \\
\hline Thick carbonaceous slate & 1.5 & 36.1 & 0.18 & 3.62 & 6.81 \\
Thin layer carbonaceous & 0.84 & 27.5 & 0.04 & 0.92 & 2.42 \\
slate & 7.81 & 35.2 & 1.31 & 21.09 & 18.11 \\
Porphyry & 4.79 & 24.2 & 0.13 & 3.36 & 4.29 \\
$\begin{array}{l}\text { Basalt limestone } \\
\text { interbedding }\end{array}$ & & &
\end{tabular}

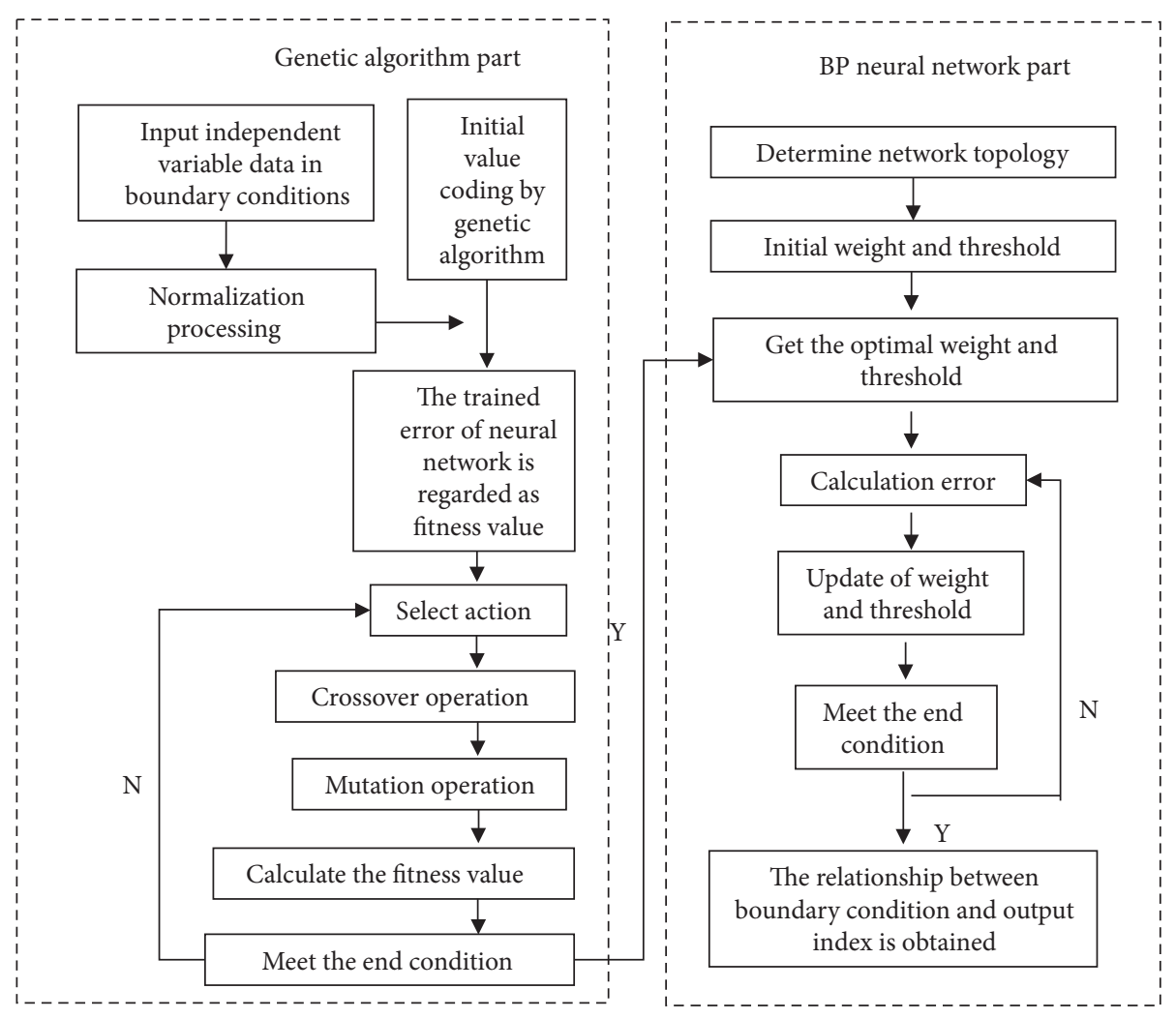

Figure 5: In situ stress inversion process.

TABLE 3: Sum of errors between numerical simulation and measurement under different numerical simulation experimental schemes.

\begin{tabular}{|c|c|c|c|c|c|c|c|}
\hline Factor & $k$ & $a$ & $b$ & $c$ & $w$ & $v$ & The absolute value \\
\hline Experiment 1 & 0.1 & 0.1 & 0.1 & 0.1 & 0.1 & 0.001 & 112.468 \\
\hline Experiment 2 & 0.1 & 0.5 & 0.5 & 0.5 & 0.5 & 0.005 & 85.478 \\
\hline Experiment 3 & 0.1 & 0.9 & 0.9 & 0.9 & 0.9 & 0.009 & 60.636 \\
\hline Experiment 4 & 0.1 & 1.3 & 1.3 & 1.3 & 1.3 & 0.013 & 386.995 \\
\hline Experiment 5 & 0.1 & 1.7 & 1.7 & 1.7 & 1.7 & 0.017 & 416.205 \\
\hline Experiment 6 & 0.5 & 0.1 & 0.5 & 0.9 & 1.3 & 0.017 & 33.385 \\
\hline Experiment 7 & 0.5 & 0.5 & 0.9 & 1.3 & 1.7 & 0.001 & 5.492 \\
\hline Experiment 8 & 0.5 & 0.9 & 1.3 & 1.7 & 0.1 & 0.005 & 10.358 \\
\hline Experiment 9 & 0.5 & 1.3 & 1.7 & 0.1 & 0.5 & 0.009 & 59.415 \\
\hline Experiment 10 & 0.5 & 1.7 & 0.1 & 0.5 & 0.9 & 0.013 & 38.122 \\
\hline Experiment 11 & 0.9 & 0.1 & 0.9 & 1.7 & 0.5 & 0.013 & 128.066 \\
\hline Experiment 12 & 0.9 & 0.5 & 1.3 & 0.1 & 0.9 & 0.017 & 144.647 \\
\hline Experiment 13 & 0.9 & 0.9 & 1.7 & 0.5 & 1.3 & 0.001 & 87.695 \\
\hline Experiment 14 & 0.9 & 1.3 & 0.1 & 0.9 & 1.7 & 0.005 & 171.750 \\
\hline
\end{tabular}


TABle 3: Continued.

\begin{tabular}{lccccccc}
\hline Factor & $k$ & $a$ & $b$ & $c$ & $w$ & $v$ & The absolute value \\
\hline Experiment 15 & 0.9 & 1.7 & 0.5 & 1.3 & 0.1 & 0.009 & 101.702 \\
Experiment 16 & 1.3 & 0.1 & 1.3 & 0.5 & 1.7 & 0.009 & 186.289 \\
Experiment 17 & 1.3 & 0.5 & 1.7 & 0.9 & 0.1 & 0.013 & 199.758 \\
Experiment 18 & 1.3 & 0.9 & 0.1 & 1.3 & 0.5 & 0.017 & 238.704 \\
Experiment 19 & 1.3 & 1.3 & 0.5 & 1.7 & 0.9 & 0.001 & 223.913 \\
Experiment 20 & 1.3 & 1.7 & 0.9 & 0.1 & 1.3 & 0.009 & 366.241 \\
Experiment 21 & 1.7 & 0.1 & 1.7 & 1.3 & 0.9 & 0.005 & 304.802 \\
Experiment 22 & 1.7 & 0.5 & 0.1 & 1.7 & 1.3 & 0.009 & 263.651 \\
Experiment 23 & 1.7 & 0.9 & 0.5 & 0.1 & 1.7 & 0.013 & 322.965 \\
Experiment 24 & 1.7 & 1.3 & 0.9 & 0.5 & 0.1 & 0.017 & 338.985 \\
Experiment 25 & 1.7 & 1.7 & 1.3 & 0.9 & 0.5 & 0.001 & 283.951 \\
\hline
\end{tabular}
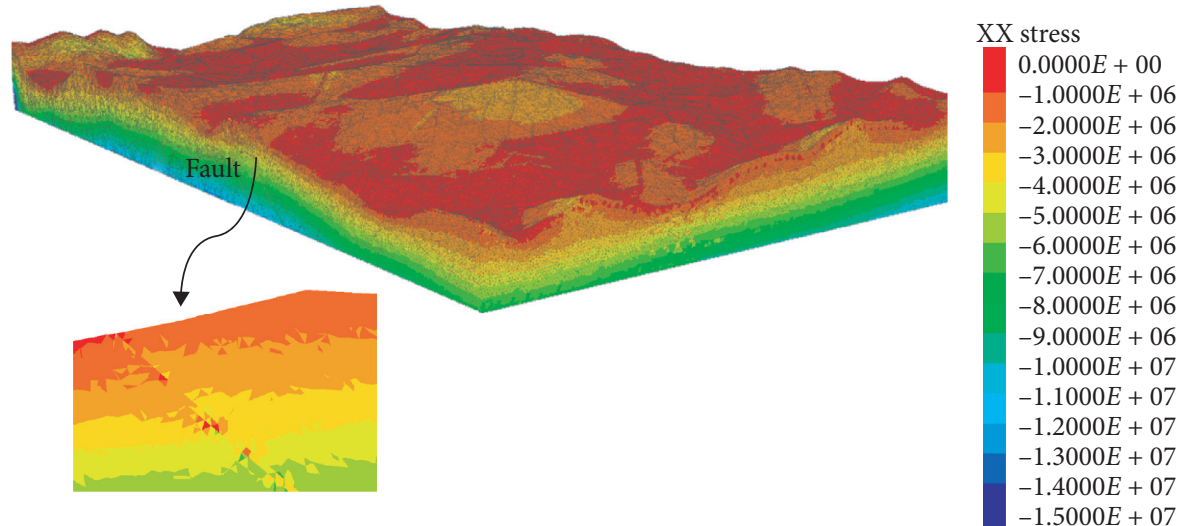

Figure 6: Horizontal in situ stress component in $X$ direction (E-W direction).

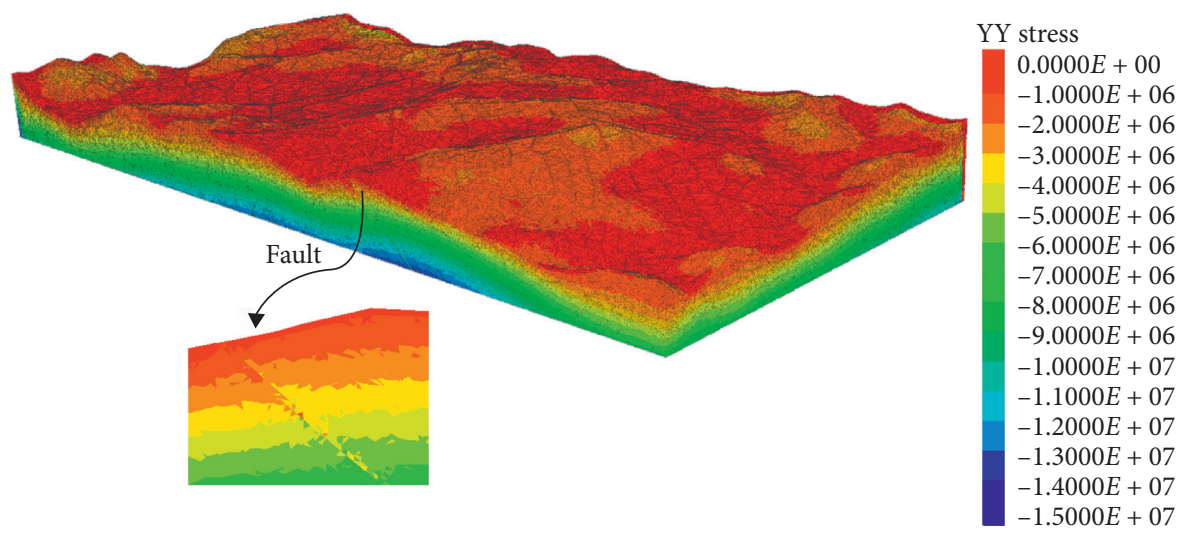

Figure 7: Horizontal in situ stress component in $Y$ direction (N-S direction).

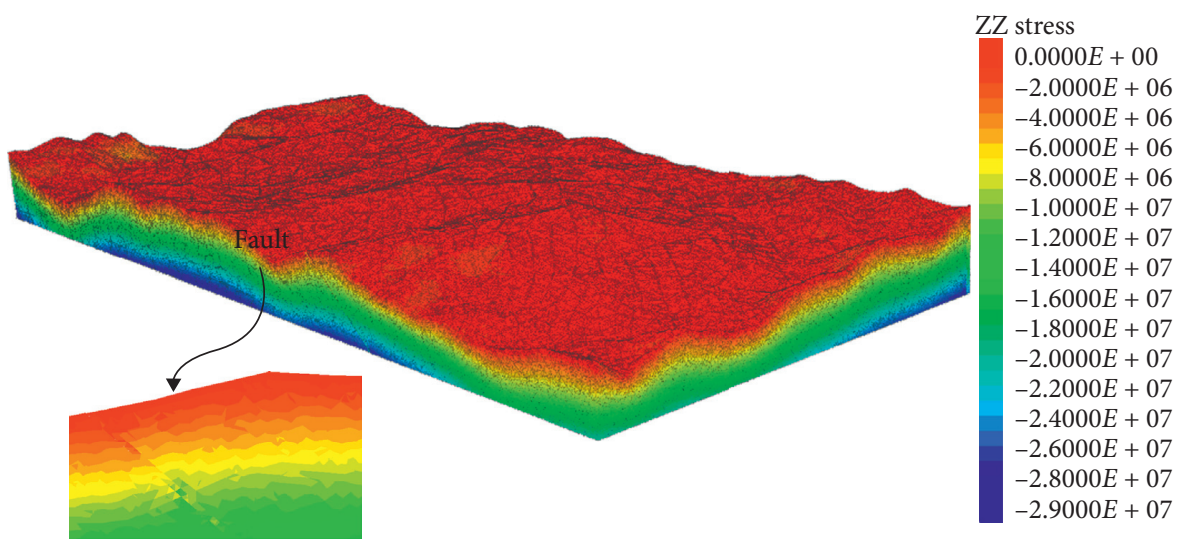

Figure 8: Vertical in situ stress. 
small, the hanging wall forms the stress concentration area, and the footwall forms the stress relaxation area.

The vertical stress of Jingzhai tunnel near the fault area is $17 \sim 18 \mathrm{MPa}$, the horizontal stress in $X$ direction is $9 \sim 10 \mathrm{MPa}$, the horizontal stress in $Y$ direction is $10 \sim 11 \mathrm{MPa}$, and the maximum horizontal principal stress is $13.5 \sim 14.8 \mathrm{MPa}$. Due to the influence of faults, the properties of surrounding rock in this area are crossed, and large deformation of surrounding rock is easy to occur. According to the in situ stress, it is considered that the dangerous section in the large deformation area of the tunnel is buried more than $500 \mathrm{~m}$ and the fault area is $200 \mathrm{~m}$.

\section{Conclusion}

The measured in situ stress shows that the in situ stress in Jingzhai tunnel area is high and there is a large difference between the maximum horizontal principal stress and the minimum horizontal principal stress, and the shear stress is high. A three-dimensional numerical model is established according to the terrain characteristics, and the influence of fault structure on in situ stress is considered. By establishing the boundary conditions of the numerical model with free variables, the errors between the simulated and measured values of in situ stress under different boundary conditions are analyzed.

Through the neural network model based on genetic algorithm optimization, the optimal boundary conditions are analyzed. According to the boundary conditions, the distribution of the whole in situ stress is analyzed. There is a significant relationship between in situ stress distribution and burial depth. Faults also have a significant effect on the distribution of in situ stress. In the process of construction, the buried depth of more than $500 \mathrm{~m}$ and the fault area of $200 \mathrm{~m}$ should be divided into large deformation dangerous area.

\section{Data Availability}

The data are available and explained in this article; readers can access the data supporting the conclusions of this study.

\section{Conflicts of Interest}

The author declares that there are no conflicts of interest.

\section{Acknowledgments}

The author gratefully acknowledges the funding provided by Shanxi Provincial Science and Technology Program ([2018] 1056).

\section{References}

[1] N. Xu, C. A. Li, L. C. Zhou, Z. Sha, C. Liang, and J. Y. Yang, "Microseismic monitoring and stability analysis of the left bank slope in Jinping first stage hydropower station in southwestern China," International Journal of Rock Mechanics and Mining Sciences, vol. 48, no. 6, pp. 950-963, 2011.
[2] G. Li, Y. Hu, Q.-B. Li, T. Yin, J.-X. Miao, and M. Yao, "Inversion method of in-situ stress and rock damage characteristics in dam site using neural network and numerical simulation-a case study," IEEE Access, vol. 8, pp. 46701-46712, 2020.

[3] H. Zhao, F. Ma, J. Xu, and J. Guo, "In situ stress field inversion and its application in mining-induced rock mass movement," International Journal of Rock Mechanics and Mining Sciences, vol. 53, pp. 120-128, 2012.

[4] L. Gan, M. Weibin, and T. Siming, "Effects of high-pretension support system on soft rock large deformation of perpendicularly crossing tunnels," Advances in Civil Engineering, vol. 2020, Article ID 6669120, 18 pages, 2020.

[5] Q. Wang, H. K. Gao, B. Jiang, S. C. Li, M. C. He, and M. C. Qin, "In-situ test and bolt-grouting design evaluation method of underground engineering based on digital drilling," International Journal of Rock Mechanics and Mining Sciences, vol. 138, Article ID 104575, 2021.

[6] Y. Ning, H. Tang, J. V. Smith, B. Zhang, P. Shen, and G. Zhang, "Study of the in situ stress field in a deep valley and its influence on rock slope stability in southwest China," Bulletin of Engineering Geology and the Environment, vol. 21, pp. 1-20, 2021.

[7] W. Ju, Z. Yang, Y. Qin, T. Yi, and Z. Zhang, "Characteristics of in-situ stress state and prediction of the permeability in the Upper Permian coalbed methane reservoirwestern Guizhou region SW China," Journal of Petroleum Science and Engineering, vol. 165, pp. 199-211, 2018.

[8] H. Huang, T. Babadagli, X. Chen, X. Z. Li, and Y. M. Zhang, "Performance comparison of novel chemical agents for mitigating water-blocking problem in tight gas sandstones," SPE Reservoir Evaluation \& Engineering, vol. 23, no. 4, pp. 1150-1158, 2020.

[9] B. Li, R. Bao, Y. Wang, R. Liu, and C. Zhao, "Permeability evolution of two-dimensional fracture networks during shear under constant normal stiffness boundary conditions," Rock Mechanics and Rock Engineering, vol. 54, no. 3, pp. 1-20, 2021.

[10] G. Li, W. Ma, S. Tian, Z. Hongbo, F. Huabin, and W. Zou, "Groundwater inrush control and parameters optimization of curtain grouting reinforcement for the Jingzhai tunnel," Geofluids, vol. 2021, pp. 192-203, 2021.

[11] W. Ju and K. Wang, "A preliminary study of the present-day in-situ stress state in the Ahe tight gas reservoirDibei gasfieldKuqa depression," Marine and Petroleum Geology, vol. 96, pp. 154-165, 2018.

[12] N. Xu, J. Zhang, H. Tian, G. Mei, and Q. Ge, "Discrete element modeling of strata and surface movement induced by mining under open-pit final slope," International Journal of Rock Mechanics and Mining Sciences, vol. 88, pp. 61-76, 2016.

[13] Q. Wang, Q. Qin, B. Jiang et al., "Mechanized construction of fabricated arches for large-diameter tunnels," Automation in Construction, vol. 124, Article ID 103583, 2021.

[14] S. S. Zhifei, S. Yun-jiang, and L. Xuan, "Research on in situ stress measurement and inversionand its influence on roadway layout in coal mine with thick coal seam and large mining height," Geotechnical and Geological Engineering, vol. 36, no. 3, pp. 1907-1917, 2018.

[15] Y. Zhou, Z. Zhao, C. Liu, X. Jiang, and D. Ma, "Inversion analysis of crustal stress distribution law in gully geomorphic mining area," Geotechnical and Geological Engineering, vol. 37, no. 5, pp. 4075-4087, 2019.

[16] L. Wang, S. Liu, Y.-P. Cheng, G.-z. Yin, P.-k. Guo, and J.-h. Mou, "The effects of magma intrusion on localized stress 
distribution and its implications for coal mine outburst hazards," Engineering Geology, vol. 218, pp. 12-21, 2017.

[17] Y. Wang, B. Zhang, S. H. Gao, and C. H. Li, "Investigation on the effect of freeze-thaw on fracture mode classification in marble subjected to multi-level cyclic loads," Theoretical and Applied Fracture Mechanics, vol. 111, Article ID 102847, 2017.

[18] Q.-X. Meng, W.-Y. Xu, H.-L. Wang, X.-Y. Zhuang, W.-C. T. Xie, and T. Rabczuk, "DigiSim - an open source software package for heterogeneous material modeling based on digital image processing," Advances in Engineering Software, vol. 148, Article ID 102836, 2020.

[19] Z. Tao, C. Zhu, M. He, and M. Karakus, "A physical modelingbased study on the control mechanisms of negative poisson's ratio anchor cable on the stratified toppling deformation of anti-inclined slopes," International Journal of Rock Mechanics and Mining Sciences, vol. 138, Article ID 104632, 2021.

[20] S. Ding, C. Su, and J. Yu, “An optimizing BP neural network algorithm based on genetic algorithm," Artificial Intelligence Review, vol. 36, no. 2, pp. 153-162, 2011.

[21] Q. Jiang, R. Huang, Y. Huang et al., "Application of BP neural network based on genetic algorithm optimization in evaluation of power grid investment risk," IEEE Access, vol. 7, pp. 154827-154835, 2019.

[22] H. Huang, T. Babadagli, H. Z. Li, K. Develi, and D. S. Zhou, “A visual experimental study on proppants transport in rough vertical fractures," International Journal of Rock Mechanics and Mining Sciences, vol. 134, Article ID 104446, 2020.

[23] R. Jiang, F. Dai, Y. Liu, and A. Li, "Fast marching method for microseismic source location in cavern-containing rockmass: performance analysis and engineering application," Engineering, vol. 10, pp. 128-139, 2021.

[24] Z. Tao, C. Zhu, X. Zheng et al., "Failure mechanisms of soft rock roadways in steeply inclined layered rock formations," GeomaticsNatural Hazards and Risk, vol. 9, no. 1, pp. 11861206, 2018.

[25] Z. Tao, C. Zhu, X. H. Zheng, and M. C. He, "Slope stability evaluation and monitoring of Tonglushan ancient copper mine relics," Advances in Mechanical Engineering, vol. 10, pp. 168-179, 2018. 